\title{
Study of pattern of common chief complaints in patients seeking dental care in private dental institution of Andhra Pradesh, India
}

\author{
Krishnaveni Marella \\ Postgraduate, Dept. of Conservative Dentistry and Endodontics, G Pulla Reddy dental College and Hospital, Kurnool, Andhra \\ Pradesh, India
}

*Corresponding Author:

Email: krishnavenimds@gmail.com

\begin{abstract}
Introduction: Provision of proper dental health care depends on many factors like health manpower, infrastructure and compliance from the patients. Among all these the demand for dental health care is usually represented by chief complaints (CCs) form the patient which makes the basic pillar for further evaluation and management.

Aims and Objectives: To find out the pattern of chief complaints by the dental patients attending the private dental institution in Andhra Pradesh.

Materials and method: A hospital based cross sectional study was conducted at G Pulla Reddy Dental College and Hospital, Kurnool Andhra Pradesh in the month of July 2017. Details regarding age, sex and chief complaints or the reason for visiting the hospital was collected.

Results: A total of 1308 visited the hospital during the study period and all of them were included in the study. The demand for treatment was majorly from the 21-30 years age group (27.52\%) followed by 31-40years and 11-20years age group. Toothache $(32.3 \%)$ was the most common CC followed by decayed tooth (19.1\%), wants to remove tooth (9.5\%). The elderly age group had $\mathrm{CC}$ in the form of toothache $(31.48 \%)$; wants remove the tooth $(22.22 \%)$ followed by loose tooth $(18.51 \%)$.

Conclusion: From this study it can be concluded that there are variations in dental visits with respect to different age groups and gender. Large scale studies with complete and accurate data collection will definitely aid dental care in a manner by which dental health care programmes at national level can effectively implemented.
\end{abstract}

Keywords: Chief Complaints, Dental, Treatment seeking.

\section{Introduction}

Provision of proper dental health care depends on many factors like health manpower, infrastructure and compliance from the patients. Among all these the demand for dental health care is usually represented by chief complaints (CCs) form the patient which makes the basic pillar for further evaluation and management. ${ }^{1}$

It means the patient's perceptions are recorded in his/her own words which can be translated into demand for dental care. ${ }^{2}$

Various epidemiological studies have reported about the magnitude and severity of dental disorders among population by which the felt need or perceived need can be estimated.

The process of health seeking behavior for dental diseases and priority to treat them depends upon the problems that makes the patient to consult the dental practititoners. ${ }^{3}$ However very studies have been conducted to know about the chief complaints of dental patients in our country. Therefore this study was undertaken to find out the pattern of chief complaints by the dental patients attending the private dental institution in Andhra Pradesh.

\section{Materials and Method}

A hospital based cross sectional study was conducted at G Pulla Reddy Dental College and Hospital, Kurnool Andhra Pradesh in the month of July 2017 2017. Patients were explained about the purpose of the study and informed consent was obtained. Details regarding age, sex and chief complaints or the reason for visiting the hospital was collected. A total of 1308 visited the hospital during the study period and all of them were included in the study.

\section{Results}

The mean age of the study participants was 28.3 years. Females contributed a higher percentage $(51.8 \%)$ for treatment seeking when compared to males (48.2\%) (Table 1). The demand for treatment was majorly from the 21-30 years age group (27.52\%) followed by 3140years and 11-20years age group. There was statistically significant difference observed with respect to gender wise demand for seeking dental care $(\mathrm{p}<0.005)$.

Table 2 depicts the gender wise distribution of study subjects according to the chief complaints. Toothache $(32.3 \%)$ was the most common CC followed by decayed tooth $(19.1 \%)$, wants to remove tooth $(9.5 \%)$, the other chief complaints like broken filling, bad breath, dental checkup were uncommon reasons for seeking dental care.

Age wise distribution of chief complaints is shown in Table 3. The most common complaint reported by all age groups except in 1-10 years was toothache (32.49\%) wherein decayed tooth was the common chief complaint. The second most common CC reported was 
decayed tooth in all groups except in age group more than 50 years in which "wants to remove the tooth" as CC.

We noticed that according to the $\mathrm{CC}$ decayed tooth (41\%) was highest in 1-10 years age group whereas wants to clean the teeth, filling the decayed tooth and want of dental clip were highest CCs in 11-20years, seeking dental check (1.38\%) was more common CC in the 21-30years age group when compared to others. The elderly age group had $\mathrm{CC}$ in the form of toothache $(31.48 \%)$, wants remove the tooth $(22.22 \%)$ followed by loose tooth(18.51\%).

\section{Discussion}

Our study reported that toothache $(32.3 \%)$ was the most common reason for seeking dental treatment which was similar to study by Thangadurai $\mathbf{M}^{1}$ (2015) among dental care facility at Pondicherry where it was around $32.5 \%$. Studies done by Razak IA ${ }^{4}(1987)$, Van Palenstein $^{5}$ (1990), Broughton $\mathrm{AM}^{6}$ (1991), Mosha $\mathrm{HJ}^{7}$ (1993), Oginni $\mathrm{AO}^{8}(2004)$ and by Abdullah $\mathrm{BA}^{9}$ (2007) reported the same findings with range from $28.3 \%$ to $42.1 \%$.

Our study also noticed that decayed tooth (20.9\%) was the second most reason visiting the dental care in 11-20 age group which was similar to findings reported in the study by $n$ Ekanayake $\mathrm{L}^{10}(2001)$. This is probably because of poor oral hygiene. In the same group it was observed that orthodontic treatment demand was high particularly in females which similar to study by Abdullah $\mathrm{BA}^{9}(2007)$.

In our study noticed that the demand for restorative care was high 21-30 whereas demand for prosthetics was more in 41-50 years and demand for extraction in elderly age group. Oginni $\mathrm{AO}^{8}$ (2004) reported similar findings with respected $\mathrm{CC}$ of elderly group. Therefore it can be said that demand for seeking dental care varies according to age.

Very few ( 12 out of 1308) patients had the reason of "dental check up" for visiting the dental health care which shows lack of awareness among young population for checkups and preventive dental care which is a common concern in developing countries, Freeman $\mathrm{R}^{11}$ (1999) also reported the same.

Our study reported that acute conditions like pain was the apparent reason for seeking treatment most of the time which is due to late stage presentation to dental clinic which can be related to factors such as anxiety, financial costs lack of access. This was similar to study by Pekiner $F^{12}$ (2010) and also by Kakatkar $G$ et al ${ }^{13}$ (2011). Kadaluru $\mathrm{UG}^{14}$ (2012) reported that cost was the major barrier for dental care utilization.

One of the limitation of our study is a single dental hospital based study. Correlating with the socioeconomic factors could have given better insight into the underlying reasons for not seeking the care. A large scale multi centric study involving public dental hospitals supported good data collection will facilitate in depth findings.

Table 1: Distribution of subjects according to age group and gender

\begin{tabular}{|l|c|c|c|}
\hline $\begin{array}{l}\text { Age group } \\
\text { (in years) }\end{array}$ & Males n (\%) & Females n(\%) & Total n(\%) \\
\hline $0-10$ & $99(15.82)$ & $96(14.21)$ & $195(14.9)$ \\
\hline $11-20$ & $140(22.31)$ & $139(20.53)$ & $279(21.33)$ \\
\hline $21-30$ & $163(25.89)$ & $197(29.21)$ & $360(27.52)$ \\
\hline $31-40$ & $88(14)$ & $197(29.21)$ & $285(21.78)$ \\
\hline $41-50$ & $69(10.9)$ & $139(20.62)$ & $208(15.90)$ \\
\hline $51-60$ & $39(6.2)$ & $49(7.21)$ & $88(6.72)$ \\
\hline$>60$ & $33(5.22)$ & $21(3.10)$ & $54(4.13)$ \\
\hline Total & $\mathbf{6 3 1}(\mathbf{1 0 0})$ & $\mathbf{6 7 7 ( 1 0 0 )}$ & $\mathbf{1 3 0 8}(\mathbf{1 0 0})$ \\
\hline $\mathrm{X}^{2}=19.3, \mathrm{p}<0.005$ & \\
\hline
\end{tabular}

Table 2: Distribution of the chief complaints according to sex $n(\%)$

\begin{tabular}{|l|c|c|c|}
\hline \multicolumn{1}{|c|}{ Chief complaint } & $\begin{array}{c}\text { Male } \\
(\boldsymbol{n = 6 3 1})\end{array}$ & $\begin{array}{c}\text { Female } \\
(\boldsymbol{n = 6 7 7})\end{array}$ & $\begin{array}{c}\text { Total } \\
(\boldsymbol{n = 1 3 0 8})\end{array}$ \\
\hline Toothache & $194(30.8)$ & $228(33.7)$ & $422(32.3)$ \\
\hline Decayed tooth & $98(15.6)$ & $152(22.4)$ & $250(19.1)$ \\
\hline Wants to remove the tooth & $61(9.7)$ & $63(9.3)$ & $124(9.5)$ \\
\hline Wants to clean the teeth & $43(6.8)$ & $28(4.1)$ & $71(5.4)$ \\
\hline Wants to fill the decayed tooth & $29(4.6)$ & $36(5.3)$ & $65(4.9)$ \\
\hline Wants to replace the missing tooth & $32(5.1)$ & $16(2.4)$ & $48(3.7)$ \\
\hline Wants to wear clip & $11(1.7)$ & $33(4.9)$ & $44(3.4)$ \\
\hline Loose tooth & $20(3.2)$ & $20(3.0)$ & $40(3.0)$ \\
\hline Sensitivity & $17(2.7)$ & $12(1.8)$ & $29(2.2)$ \\
\hline Forwardly placed front teeth & $11(1.7)$ & $15(2.2)$ & $26(2)$ \\
\hline
\end{tabular}




\begin{tabular}{|l|c|c|c|}
\hline Bleeding gum & $14(2.2)$ & $11(1.6)$ & $25(1.9)$ \\
\hline Pain in the gum & $16(2.5)$ & $5(0.7)$ & $21(1.6)$ \\
\hline Unerupted upper front teeth & $13(2.1)$ & $3(0.4)$ & $16(1.2)$ \\
\hline Broken filling & $8(1.2)$ & $5(0.7)$ & $13(0.9)$ \\
\hline Irregularly placed front teeth & $7(1.1)$ & $6(0.9)$ & $13(0.9)$ \\
\hline Dental check up & $7(1.1)$ & $5(0.7)$ & $12(0.9)$ \\
\hline Swollen gum & $9(1.4)$ & $3(0.4)$ & $12(0.9)$ \\
\hline Others & $11(1.7)$ & $36(5.3)$ & $47(3.7)$ \\
\hline
\end{tabular}

Table 3: Distribution of the chief complaints according to age group $\mathbf{n}(\%)$

\begin{tabular}{|c|c|c|c|c|c|c|c|c|}
\hline & $\begin{array}{c}0-10 \\
(n=195)\end{array}$ & $\begin{array}{c}11-20 \\
(n=279)\end{array}$ & $\begin{array}{c}21-30 \\
(n=360)\end{array}$ & $\begin{array}{c}31-40 \\
(n=285)\end{array}$ & $\begin{array}{c}41-50 \\
(n=208)\end{array}$ & $\begin{array}{c}51-60 \\
(n=88)\end{array}$ & $\begin{array}{c}>60 \\
(n=54)\end{array}$ & $\begin{array}{c}\text { All Ages } \\
(n=1308)\end{array}$ \\
\hline Toothache & $6(23.5)$ & $60(21.5)$ & $129(35.83)$ & $110(38.5)$ & $86(41.34)$ & $38(43.18)$ & $17(31.48)$ & $425(32.49)$ \\
\hline Decayed tooth & $2(41.0)$ & $58(20.78)$ & $60(16.66)$ & $43(15.08)$ & $21(10.09)$ & $4(4.54)$ & $0(0.0)$ & $248(19.32)$ \\
\hline $\begin{array}{l}\text { Wants to } \\
\text { remove the } \\
\text { tooth }\end{array}$ & $2(1.02)$ & 11(3.9) & $36(10)$ & $40(14.03)$ & $21(10.09)$ & $15(17.04)$ & $12(22.22)$ & $122(9.32)$ \\
\hline $\begin{array}{l}\text { Wants to clean } \\
\text { the teeth }\end{array}$ & $5(2.56)$ & $22(7.88)$ & $24(6.66)$ & $17(5.96)$ & $7(3.36)$ & $1(1.13)$ & $0(0.0)$ & $70(5.35)$ \\
\hline $\begin{array}{l}\text { Wants to fill } \\
\text { the decayed } \\
\text { tooth }\end{array}$ & $0(0.0)$ & $23(8.24)$ & $27(7.5)$ & $9(3.15)$ & $7(3.36)$ & $1(1.13)$ & $0(0.0)$ & $62(4.74)$ \\
\hline $\begin{array}{l}\text { Wants to } \\
\text { replace the } \\
\text { missing teeth }\end{array}$ & $1(0.62)$ & $5(1.79)$ & $12(3.33)$ & $9(3.15)$ & 21(10.09) & $4(4.54)$ & $5(9.25)$ & $47(3.59)$ \\
\hline $\begin{array}{l}\text { Wants to wear } \\
\text { clip }\end{array}$ & $5(2.56)$ & $26(9.31)$ & $10(2.77)$ & $1(0.35)$ & $0(0.0)$ & $0(0.0)$ & $0(0.0)$ & $43(3.28)$ \\
\hline Loose tooth & $6(3.07)$ & $2(0.71)$ & $0(0.0)$ & $9(3.15)$ & $7(3.36)$ & $8(9.09)$ & $10(18.51)$ & $39(3.0)$ \\
\hline Sensitivity & $0(0.0)$ & $3(1.07)$ & $11(3.05)$ & $6(2.10)$ & $7(3.36)$ & $4(4.54)$ & $0(0.0)$ & $28(2.98)$ \\
\hline $\begin{array}{l}\text { Forwardly } \\
\text { placed front } \\
\text { teeth }\end{array}$ & $7(3.58)$ & $15(5.37)$ & $2(0.55)$ & $1(0.35)$ & $0(0.0)$ & $0(0.0)$ & $0(0.0)$ & $27(2.06)$ \\
\hline Bleeding gum & $1(0.51)$ & $7(2.50)$ & $6(1.66)$ & $9(3.15)$ & $2(0.96)$ & $1(1.13)$ & $0(0.0)$ & $26(1.98)$ \\
\hline Pain in the gum & $0(0.0)$ & $2(0.71)$ & $3(0.83)$ & $3(1.05)$ & $7(3.36)$ & $1(1.13)$ & $2(3.70)$ & $17(1.29)$ \\
\hline $\begin{array}{l}\text { Unerupted } \\
\text { upper front } \\
\text { teeth }\end{array}$ & $14(7.17)$ & $1(0.35)$ & $0(0.0)$ & $0(0.0)$ & $0(0.0)$ & $0(0.0)$ & $0(0.0)$ & $15(1.14)$ \\
\hline Broken filling & $0(0.0)$ & $3(1.07)$ & $6(1.66)$ & $1(0.35)$ & $0(0.0)$ & $1(1.13)$ & $0(0.0)$ & $13(0.99)$ \\
\hline $\begin{array}{l}\text { Irregularly } \\
\text { placed front } \\
\text { teeth }\end{array}$ & $3(1.53)$ & $6(2.15)$ & $1(0.27)$ & $0(0.0)$ & $0(0.0)$ & $0(0.0)$ & $0(0.0)$ & $11(0.84)$ \\
\hline Dental checkup & $1(0.51)$ & $1(0.35)$ & $5(1.38)$ & $1(0.35)$ & $2(0.96)$ & $0(0.0)$ & $0(0.0)$ & $10(0.76)$ \\
\hline Swollen gum & $0(0.0)$ & $2(0.71)$ & $3(0.83)$ & $0(0.0)$ & $7(3.36)$ & $(0.0)$ & $0(0.0)$ & $10(0.76)$ \\
\hline Bad breath & $0(0.0)$ & $3(1.07)$ & $1(0.27)$ & $3(1.05)$ & $2(0.96)$ & $(0.0)$ & $0(0.0)$ & $9(0.68)$ \\
\hline $\begin{array}{l}\text { Deposits in the } \\
\text { teeth }\end{array}$ & $2(1.02)$ & $2(0.71)$ & $0(0.0)$ & $3(1.05)$ & $2(0.96)$ & $0(0.0)$ & $0(0.0)$ & $9(0.68)$ \\
\hline Others & $14(7.17)$ & $14(5.01)$ & $15(4.16)$ & $12(4.12)$ & $7(3.36)$ & $5(6.68)$ & $6(11.11)$ & $70(5.4)$ \\
\hline Total & 100 & 100 & 100 & 100 & 100 & 100 & 100 & 100 \\
\hline
\end{tabular}

\section{Conclusion}

From this study it can be concluded that there are variations in dental visits with respect to different age groups and gender. Large scale studies with complete and accurate data collection will definitely aid dental care in a manner by which dental health care programmes at national level can effectively implemented.

\section{References}

1. Maheswaran T, Ramesh V, Krishnan A, Joseph J. Common chief complaints of patients seeking treatment in the government dental institution of Puducherry, India. J Indian Acad Dent Spec Res 2015;2:55-8.

2. Martin SG, Glick M. Burket's Oral Medicine: Diagnosis and Treatment. $10^{\text {th }}$ ed. New York: BC Decker INC;2003.

3. Abdullah BA, Al-Tuhafi AA. Chief complaints of patients attending college of dentistry at Mosul University. Al-Rafidain Dent J 2007;7(2):201-5.

4. Razak IA, Jaafar N. Dental needs, demands and patterns of service utilization in a selected Malaysian urban 
population. Com Dent Oral Epidemiol 1987;15:188-91.

5. Van Palenstein Helderman WH, Nathoo ZA. Dental treatment demands among patients in Tanzania. Com Dent Oral Epidemiol 199018:85-7.

6. Broughton AM, Smales RJ. Comparison of dental needs with the treatments actually received. Aust Dent $J$ 1991;36:223-30.

7. Mosha HJ, Ngilisho LA, Nkwera H, Scheutz F, Poulsen S. Oral health status and treatment needs in different age groups in two regions of Tanzania. Com Dent Oral Epidemiol 1993;22:307-10.

8. Oginni AO. Dental care needs and demands in patients attending the dental hospital of the Obafemi Awolowo University Teaching Hospital's Complex Ile-Ife, Nigeria. Niger J Med 2004;13:339-44.

9. Abdullah BA, Al-Tuhafi AA. Chief complaints of patients attending college of dentistry at Mosul University. Al-Rafidain Dent J 2007;7:201-5.

10. Ekanayake L, Weerasekare C, Ekanayake N. Needs and demands for dental care in patients attending the University Dental Hospital in Sri Lanka. Int Dent J 2001;51:67-72.

11. Freeman R. Barriers to accessing dental care: Patient factors. Br Dent J 1999;187:141-4.

12. PekinerF, GumruB, Borahan MO, AytugarE. Evaluation of demands and needs for dental care in a sample of the Turkish Population. Eur J Dent 2010;4:143-9.

13. Kakatkar G, Bhat N, Nagarajappa R, Prasad V, Sharda A, Asawa K, et al. Barriers to the utilization of dental services in Udaipur, Ind $J$ of Dent (Tehran, Iran) 2011;8:81-9.

14. Kadaluru UG, Kempraj VM, Muddaiah P. Utilization of oral health care services among adults attending community outreach programs. Ind J Dent Res 2012;23:841-2. 